Journal of Physics and Its Applications

Journal homepage : https://ejournal2.undip.ac.id/index.php/jpa/index

\title{
Characteristics of Bolus Using Silicone Rubber with Silica Composites for Electron Beam Radiotherapy
}

\author{
Santi Yuli Astuti1 ${ }^{1}$, Heri Sutanto ${ }^{1,2,}$, Eko Hidayanto ${ }^{1,2}$, Gede Wiratma Jaya ${ }^{1,2}$, Astri Suppa Supratman ${ }^{1}$, Galih Puspa \\ Saraswati ${ }^{3}$ \\ ${ }_{1}$ Departement of Physics, Faculty of Science and Mathematics, Diponegoro University, Jalan Prof.Soedarto, Tembalang, Semarang, Jawa \\ Tengah 50275, Indonesia \\ ${ }_{2}$ Smart Materials Research Center (SMARC) Diponegoro University, Prof.Soedarto, Tembalang, Semarang, Jawa Tengah 50275, Indonesia \\ ${ }_{3}$ Radiotherapy Installation, Ken Saras Hospital, Jalan Soekarno-Hatta KM.29, Bergas, Jawa Tengah 50552, Indonesia \\ *Email: herisutanto@fisika.undip.ac.id
}

\section{A R T I C L E I N F O}

\section{Article history:}

Received : September 2018

Accepted : November 2018

Available online : November 2018

Keywords:

Electron beam radiotherapy

Bolus

Silicone Rubber

Silica Composites

\begin{abstract}
A B S T R A C T
Bolus is a material that equal with the tissue and functions to increase the dose radiation in surface area in external radiotherapy, which uses electron beam. In this research, bolus was made using silicone rubber (SR) material, which was mixed with silicacomposites material. The bolus with a dimension of $12 \times 12 \times 0,5 \mathrm{~cm}^{3}$ was successfully made with a various amount of silica composite $(2 \%, 4 \%, 6 \%)$. Bolus was then characterized using linear accelerator (LINAC) with an electron beam for percentage of surface dose (PSD) and using CT-Scan to measurement relative electron density (RED). The energy of electron beam used in this research was 5 and $7 \mathrm{MeV}$. The result shows that RED value increased with increasing the amount of silica composite with higher RED value amounted to 1.186 . PSD value increased with increasing the amount of silica composite, higher PSD value of energy in 5 and $7 \mathrm{MeV}$ amounted $106.82 \%$ and $106.82 \%$ and $100.34 \%$, respectively. The result certified that the silica composite material can increase the percentage of surface dose on electron beam radiotherapy.
\end{abstract}

\section{Introduction}

Linear Accelerator (LINAC) is often used in external radiotherapy process for various cancer and is planned to produce multi energy in the form of photon beam and electron beam so that this instrument can be used to treat cancer in various position [1]. Radiotherapy is an action of radiation therapy treatment in a malignant tumor (cancer) by applying ionizing radiation, such as $\mathrm{x}$-ray, gamma ray, or particle of electron with high energy $[1,2]$. The purpose of radiotherapy is to give precisely radiation dose to the cancer without giving damage effect to the health network surrounded $[3,4]$. For cancer case that placed in skin surface area, radiation beam usually uses electron beam [5]. Generally, the electron beam has a surface dose that does not reach $100 \%$, so that to upgrade the surface dose to $100 \%$ it can be realized by using material that equals with tissue, which is known as bolus. The bolus usage in external radiotherapy has a various function such as (1) upgrade surface dose of patient, (2) compensation of un-flat surface patient body, and (3) reduce penetration of secondary electron beam athealthytissue $[6,7,8]$.

To makean equal material with tissue is not easy. Many researchers used a various material such as polymer gel, HAPRC (highly absorbent polypropylene and rayon cloth), super flab, material thermoplastic, and silicone rubber (SR) $[5,9,10]$.
However, those materials has many deficiencies such as polymer gel has low density compared with water, superflab has a deficiency in refraction which is less appropriate when being applied to the patient skin. Then, HARPC is only can be used in one-time usage. For thermoplastic material, eventhough it gives best result when being positioning on anathomy, it has deficiency when thermoplastic material is ran dry and ossified so that thermoplastic is hard to reposition to surface of a patient body [911]. SR material has various superiority such as it can be formed appropriately with the form of patient body, non-toxic, non-iritation of a skin surface and it had been proved can upgrade the dose of skin surface [5]. Compared with the others previous materials, SR material can be used as an alternative material to make bolus.

In this paper, bolus was made by using SR material, which is combined with silica composite material. The usage of silica as a composite in SR was many learned in various sectors such as electronic, and sealing product with the purpose to upgrade density and characteristic of SR mecanics [1214].However, it has not ben yet applied for radiotherapy. The added of silica in SR as bolus material can increase the percentage of surface dose so the optimization in radiotherapy of a skin cancer use electron beam. 


\section{Material and Method}

\subsection{Bolus Fabrication}

Bolus was produced using SR material that originates from silicone rubber RTV-52 with catalyst is bluesil catalyst $60 \mathrm{R}$ as an amplifier of SR material and increment of silica as a composite. Silica was gained from synthesis result of geothermal power plant waste (Physics, Material Laboratory, Diponegoro University) with the purity amounted of $70 \%$. In Bolus preparation, bolus was molded using wood molding with the dimension of $12 \times 12 \times 0.5$ $\mathrm{cm}^{3}$. Bolus was produced with the composition of SR and catalyst at amount of $72 \mathrm{ml}$ and $2.9 \mathrm{ml}$, respectively. The increment of silica composite has amount of $2 \%, 4 \%$, and $6 \%$, the sample was labeled with name tag of A, B, C, and D, where Sample A is a sample with SR material without silica composite, sample B, C and D are sampled with increment of silica composite with each compliment is $2 \%, 4 \%$, and $6 \%$, respectively.

SR and silica composite material were mixed in two-time mixing process. The first mixing process was SR and silica composite materials was mixed by using mixer at around 15 minutes. The sample was then cleaned using ultrasonic at around 30 minutes with a temperature of $40{ }^{\circ} \mathrm{C}$.After cleaning process, second mixing process was made using mixer at around 6 minutes by adding a catalyst. The mixing result was poured to the mold and waited until the material is completely hard and ready to lift from the molding.

\subsection{Relative Electron Density (RED)
(n) Measurement \\ Data relative electron density (RED)was} gained from the CT-Number value that automatically gained after obtained topography image in axialscanning used CT-Scan (General Electric, USA).In taking CT-Number value was conducted as many as 10 spots of interpretation data by made region of interest (ROI) area in the form of a circle and between the taking samples are $1 \mathrm{~cm}$. After the gained CT-Number value of each sample, to find RED value used equation as follows:

$$
\begin{gathered}
\rho_{a}=1.052+0.00048 N_{C T} \\
\rho_{b}=1.000+0.001 N_{C T}
\end{gathered}
$$

with $\rho_{a}$ is RED value with CT-Number value more than $100, \rho_{b}$ is RED value with CT-Number value less than 100 , and $N_{C T}$ is CT-Number value [15]. RED value of each network can be seen in Table 1 .

Table 1. Value of relative electron density (RED) of many tissue

\begin{tabular}{ccc}
\hline Tissue & RED & Reference \\
\hline Muscle & 1.043 & {$[16]$} \\
Liver & 1.052 & {$[16]$} \\
Breast & 0.976 & {$[17]$} \\
Dense bone & 1.512 & {$[17]$} \\
\hline
\end{tabular}

2.3. Percentage of Surface Dose (PSD) Measurement

In this research, Percentage of Surface Dose (PSD) Measurement was conducted in Radiotherapy Installation, Ken Saras Hospital, Bergas, Indonesia. PSD value was gained by giving radiation of electron beam at solid phantom without using bolus and used bolus. Electron beam energy was from a linear accelerator (LINAC) (Siemens Primus, Germany) amounted 5 and $7 \mathrm{MeV}$, respectively. Applicator field used wide field $10 \times 10 \mathrm{~cm}^{2}$ and source to surface distance (SSD) arranged in a position of $100 \mathrm{~cm}$ from the solid phantom surface.

The procedure of interpretation data was conducted by put the detector of plan parallel chamber (IbaDosimetry, Sweden) above the surface and depth position of maximum $\operatorname{dose}\left(Z_{\max }\right)$ at the solid phantom. Value of $Z_{\max }$ for 5 and $7 \mathrm{MeV}$ energy is amounted $1.1 \mathrm{~cm}$ and $1.5 \mathrm{~cm}$, respectively. Data interpretation process can be seen inFig. 1 . The measurement result is content data that appeared at electrometer (IbaDosimetry, Sweden) innanocoloumb (nC) order. To measure the percentage of surface dose in the solid phantom surface, a following equation was employed:

$$
\mathrm{PSD}=Q_{s} / Q_{z \max } \times 100 \%
$$

With $Q_{s}$ is contents value that measured in surface position of solid phantom and $Q_{Z \max }$ is contents value that measured in position of $Z_{\max }$ [5].

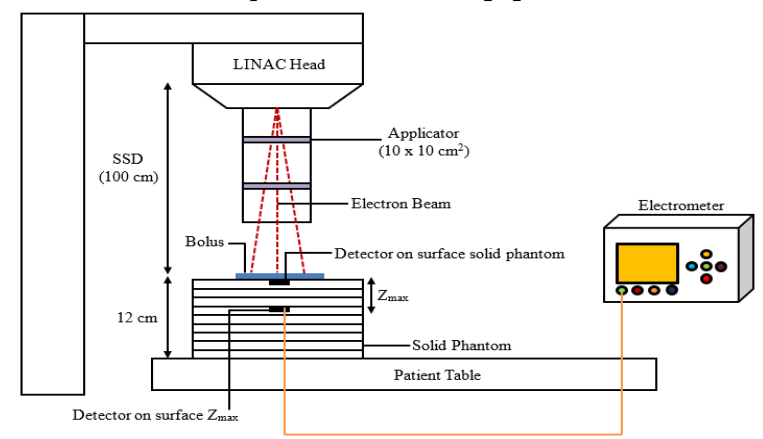

Fig 1. Scheme of percentage of surface dose (PSD) measurement

\section{Result and Discussion}

\subsection{Bolus Synthesis Results}

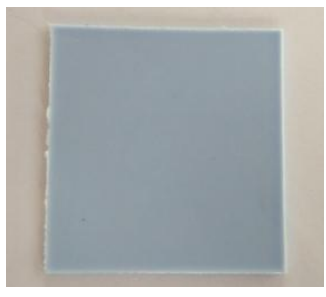

(a)

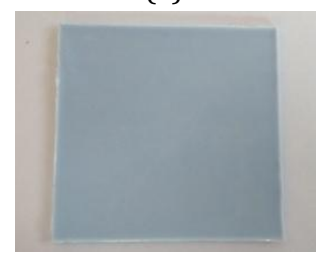

(c)

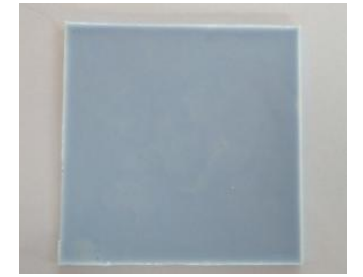

(b)

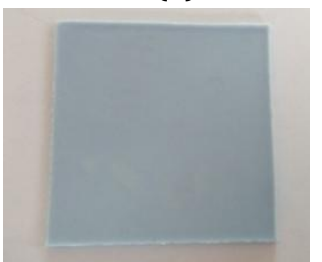

(d)
Fig 2. Bolus synthesis result (a) A sample without silica, (b) B sample with silica $2 \%$, (c) C sample with silica 4\%, 
and (d) D sample with silica 6\%

In this research, bolus is successfully made and can be seen in Fig. 2. Each sample has a flat surface and there is no air bubble on the surface. It is because in the process of bolus printing can be minimalized because the distance between molding and pouring process is near at around $10 \mathrm{~mm}$. This is also due to the assessment process during the synthesis process in the form of an cleaning process by ultrasonic.

\subsection{Bolus Tomographic Image}

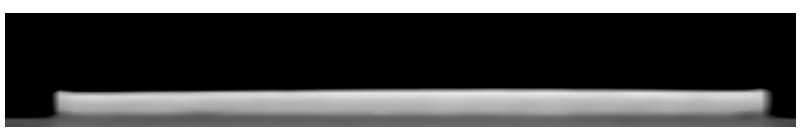

(a)

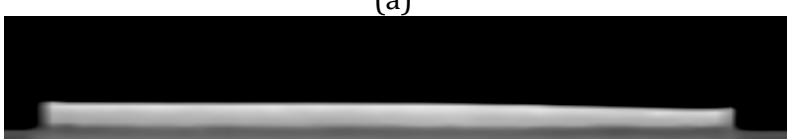

(b)

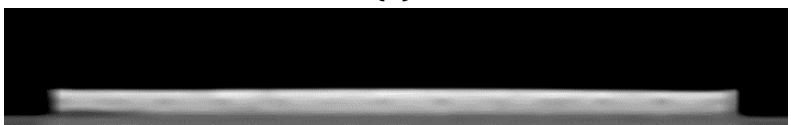

(c)

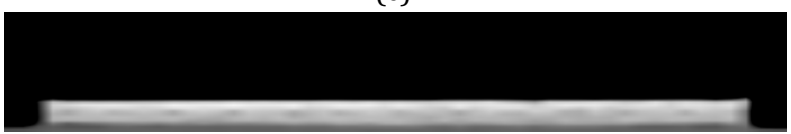

(d)

Fig 3. Bolus tomographic images in axial scanning (a) A sample without silica, (b) B sample with silica $2 \%$, (c) C sample with silica 4\%, and (d) D sample with silica $6 \%$

The axial tomographic image which obtained from CT-Scan can be seen in Fig. 3. It can be seen that each sample is homogenous and there is no air bubble. This matter shows that all samples have the main requirements of a bolus that is no air bubbles on each surface [17]. From the CT-Scan data, the HU value was also obtained, which is used to calculate the relative value of the density electron. CT-scan images show relatively similar tomography but actually have different $\mathrm{HU}$ values, namely for sampel A, B, C, D are $240,251,255,281$, respectively.

\subsection{Relative Electron Density (RED)}

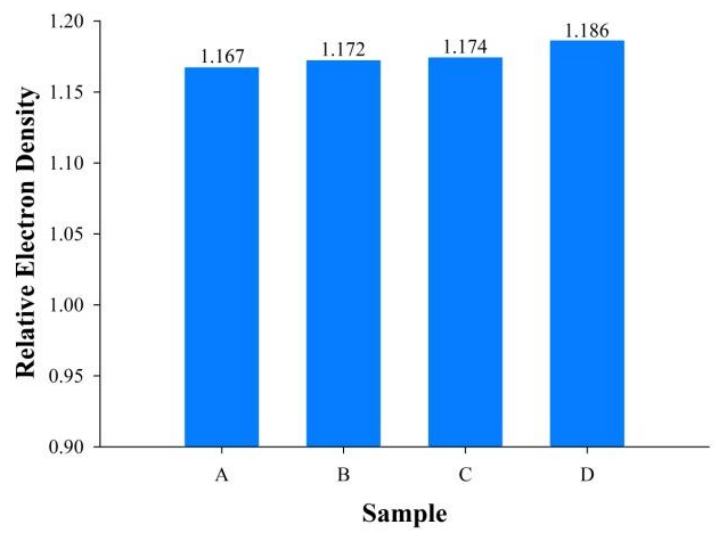

Fig4. Relative electron density (RED) graphs of each sample

The value of HU obtained for each sample is above 100 so that the RED value is calculated using Eq. (1). Relative electron density (RED) value for each sample can be seen at Fig. 4. Based on Fig. 4, sample A has RED value amounted to 1.167 while for sample B, C, and D has RED value amounted to1.172, 1.174 , and 1.186, respectively. Research result shows that much more silica composite material that used, much more increase the RED values was. This research result is appropriate with the result reported by Tarakoshi et al that used increment concentration of $\mathrm{K}_{2} \mathrm{HPO}_{4}$ solution to measure the electron density value with dual-energy $x$-ray used synchrotron radiation [18]. If compared with the RED value in Table 1, RED value for all samples is above the soft tissue such as muscle, liver, and breast, while if sample compared with solid tissue such as dense bone, RED value of sample is lower. This is because of the atom contradiction of arranging each tissue so that give different solid value to each tissue. But in entirely, the RED value of each sample is in distance of RED value tissue.

\subsection{Percentage of Surface Dose (PSD)}

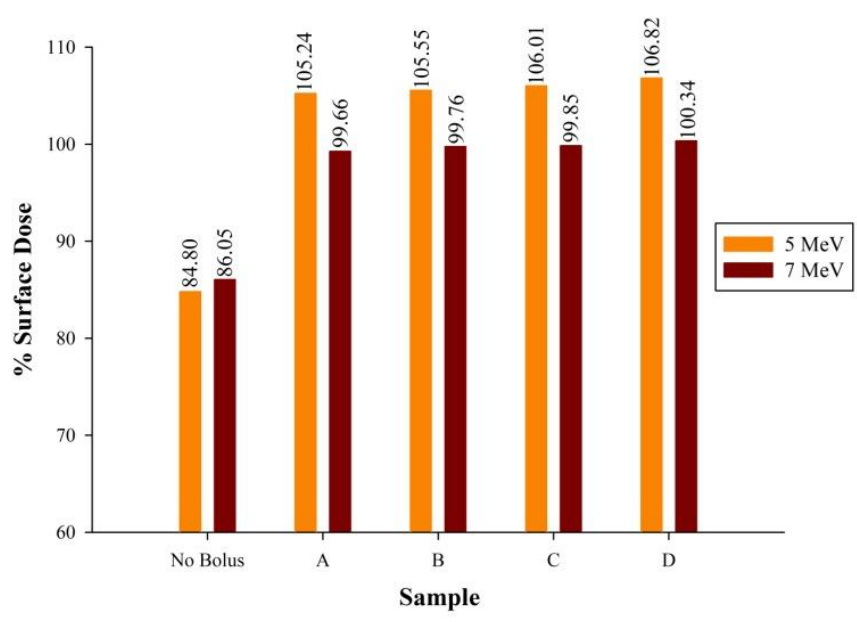

Fig 5. Percentage of surface dose (PSD) on the solid phantom surface for each sample

The value of percentage of surface dose (PSD) for each sample can be seen inFig. 5. Based on Fig. 5, PSD value without using bolus in an energy of 5 and $7 \mathrm{MeV}$ are $84.80 \%$ and $86.05 \%$, respectively. The value of PSD increased to above $100 \%$ when using a bolus of the synthesis results. From this research, the results show that much more silica composite used, the higher PSD value was so that the PSD value that produced is higher. The result can be seen in sample $\mathrm{D}$, which has higher PSD value at amount of $106.82 \%$ and $100.34 \%$ for the energy of 5 and $7 \mathrm{MeV}$, respectively. It is because of the big of density material so it had lower stopping power value if compared with the more solid material [19]. Finally, electron particle will lose kinetic energy and make dose at the surface area of solid phantom is more increased [20]. 


\section{Conclusion}

In this research, bolus was successfully made using SR material by variying the concentration of silica composite. RED value of each sample is above the soft network with higher RED value at amount of 1.186. PSD value that produced by each samples was above $100 \%$ with higher PSD value for the energy of 5 and $7 \mathrm{MeV}$ at amount of $106.82 \%$ and $100.34 \%$, respectively. The increment of silica composite in SR material can increase the RED and PSD values. Therefore, it gives optimization on radiotherapy process with an electron beam.

\section{References}

[1] D.Darmawati, S.Suharni, "Implementation of Linear Accelerator in the Treatment of Cancer Cases," Proceedings of Meeting and Scientific Presentation of Accelerator Technology and Its Application14, 36 - 47 (2012).

[2] N.Fitriyatuzzakiyyah, R.K.Sinuraya, I.M. Puspitasari, "Cancer Therapy with Radiation: Basic Concepts of Radiotherapy and Its Progression in Indonesia," Journal of Clinical Pharmacy Indonesia 6,311-320 (2017).

[3] Y. Yunasfi, M. Mudjiono, D. Irwanti, H.Hanifa, "Utilisation of Accelerator for Therapy in Indonesia," Proceding Seminar of Technology Development And Engineering Nuclear Instrumentation, 97-100 (2003).

[4] S.Suharni, F.I. Diah, P. Anggraita, "Overview of Linear Accelerator Technology (LINAC) Elekta precise in RSUP dr. Sardjito," Proceeding PPI PDIPTN, Center of Accelerator Technology and Materials Process - BATAN, Yogyakarta, 166175 (2010).

[5] I.Malaescu, C.N.Marin, M. Spunei, "Comparative Study on the Surface Dose of Some Bolus Materials," International Journal of Medical Physics, Clinical Engineering and Radiation Oncology 4, 348-352 (2015).

[6] B.G ü nhan, G.Kemikler, A. Koca, "Determination of Surface Dose and The Effect of Bolus To Surface Dose In Electron Beams," Medical Dosimetry 28, 193-198 (2003).

[7] G.W.Jaya, H. Sutanto, "Fabrication and characterization of bolus material using polydimethyl-siloxane,"Materials Research Express5, 1-8 (2018).

[8] J.W.Park,J.W. Yea, "Three-dimensional customized bolus for intensity-modulated radiotherapy in a patient with Kimura's disease involving the auricle,"Cancer/Radiothérapie20, 205-209 (2016).

[9] J.D.Adamson, T.Cooney, F.Demehri, A.Stalnecker, D.Georgas, F.F.Yin,J. Kirkpatrick,
"Characterization of Water-Clear PolymericGels for Use as Radiotherapy Bolus," Original Article, Technology in Cancer Research \& Treatment, 1-7 (2017).

[10] S.Visscher, E. Barnett, "Comparison of Bolus Material to Highly Absorbent Polypropylene and Crayon Cloth," Journal of Medical Imaging and Radiation Sciences48,55-60 (2016).

[11] K.Nagata, J.K.Lattimer, J.S. March, "The Electron Beam Attenuating Properties of Superflab, Play-Doh, and Wet Gauze, Compared to Plastic Water," Journal of the American College of Veterinary Radiology and the International Veterinary Radiology Association 53 No 1, 96-100 (2012).

[12] L.K.Namitha, M.T. Sebastian, "Fused Silica Filled Silicone Rubber Composites for Flexible Electronic Applications," International Conference on Advanced Material and Manufacturing Process for Strategic Sectors 830-831, 537-540 (2015).

[13] C.Dengke, W.Xishan, L.Lei, Y. Jianhui, "Study on RTV silicone rubbed $\mathrm{Si}_{2}$ electrical insulation nanocomposites," International Conference on Solid Dielecbics, Toulouse, France, 1-4 (2004).

[14] L.Wu, X.Wang, L.Ning, J.Han, Z.Wan, M.Lu, "Improvement of silicone rubber properties by additionof nano-SiO2 particles," Journal of Applied Biomaterial and Functional Material 14, 11-14 (2016).

[15] A.Montaseri,M.Alinaghizadeh,S.R.Mahdavi, "Physical Properties of Ethyl Methacrylate as a Bolus in Radiotherapy," Iranian Journal of Medical Physics 9, 127-134 (2012).

[16] C.B.Saw, A.Loper, K.Komanduri, T.Combine, S.Huq, C. Scicutella, "Determination of Ct-ToDensity Conversion Relationship for ImageBased Treatment Planning Systems," Medical Dosimetry30, 145-148 (2005).

[17] F.A.Lothfy, I.S.Mustafa, Z.S.Yahya, S.A. Ishak, N. M. Daud, "To Study The Durian Seed As A New Substrate For Bolus In Radiotherapy," Proceedings of Sixteenth The IIER International Conference, Kuala Lumpur, Malaysia, 110-113 (2015).

[18] M.Torikoshi, T.Tsunoo, M.Sasaki, M. Endo, Y.Noda, Y.Ohno, T. Kohno, K.Hyodo, K.Uesugi, N.Yagi,"Electron density measurement with dual-energy x-ray CT using synchrotron radiation," Physics In Medicine and Biology48, 673-685 (2003).

[19] E.B. Podgorsak, "Radiation Oncology Physics: A Handbook for Teacher and Students," Vienna: Internastional Atomic Energy Agency (2005).

[20] G.D.Lambert, N.D.Richmond, R.H.Kermode, D.J.T. Porter, "The Use of High Density Metal Foils to Increase Surface Dose in Low-Energy Clinical Electron Beams," Journal of Radiotherapy and Oncology 53, 161-166 (1999). 